\title{
Significance of Asymmetric Dimethylarginine (ADMA) Concentrations During Coronary Circulation in Patients With Vasospastic Angina
}

\author{
Tomoyuki Hori, MD; Taku Matsubara, MD; Takaharu Ishibashi, MD*; Kazuyuki Ozaki, MD; \\ Keiichi Tsuchida, MD; Tohru Mezaki, MD; Takayuki Tanaka, MD; Akimitsu Nasuno, MD; \\ Kaname Kubota, MD; Yuichi Nakamura, MD; Masaru Yamazoe, MD**; \\ Yoshifusa Aizawa, MD; Matomo Nishio, MD*
}

\begin{abstract}
The basal activity of nitric oxide (NO) is reduced in spastic arteries of patients with vasospastic angina (VSA). Elevated concentrations of ADMA are associated with reduced NO production and impaired endothelium-dependent vasodilatation. The aim of this study was to elucidate the role of ADMA and its relationship to NO end-products (NOx; nitrate + nitrite) during coronary circulation in patients with VSA. The plasma ADMA and NOx concentrations during coronary circulation were evaluated in 16 VSA and 16 control patients. Blood samples were obtained from the coronary sinus $(\mathrm{V})$ and the ostium of the left coronary artery $(\mathrm{A})$, and the $(\mathrm{V}-\mathrm{A})$ differences of ADMA and NOx were determined. The coronary sinus plasma ADMA concentration in patients with VSA was higher than that in the control. The coronary sinus -arterial $(\mathrm{V}-\mathrm{A})$ difference of NOx was negative in the VSA group and approximately zero in the control group (VSA group $=-1.4 \mu \mathrm{mol} / \mathrm{L}$, control group $=-0.1 \mu \mathrm{mol} / \mathrm{L}, \mathrm{p}=$ 0.0005). Furthermore, in the VSA patients, there was a negative correlation between the $(\mathrm{V}-\mathrm{A})$ difference of NOx and the basal coronary artery tone at the site of spasm $(\mathrm{r}=-0.60, \mathrm{p}=0.015)$. A significant negative correlation between the $(\mathrm{V}-\mathrm{A})$ differences of NOx and ADMA was observed in patients with VSA $(r=-0.52, \mathrm{p}<0.05)$, but not in those of the control. Higher ADMA concentrations might cause the reduced formation of NO that underlies the pathophysiology of coronary vasospasm. (Circ J 2003; 67: 305-311)
\end{abstract}

Key Words: Asymmetric dimethylarginine; Coronary circulation; Vasospasm

$\mathbf{T}$ he vascular endothelium plays an important role in the regulation of vascular tone by releasing several vasoactive substances, such as nitric oxide (NO) ${ }^{1-3}$ and endothelial dysfunction underlying several vascular pathological conditions has been ascribed to either reduced NO release from the endothelial cells or reduced bioavailability of NO. Indeed, a decrease in the bioavailability of endothelium-derived $\mathrm{NO}$ has been demonstrated in patients with cardiovascular risk factors ${ }^{4}$ and Quyyumi et al have suggested that the basal activity of NO is reduced in the human atherosclerotic epicardial and microvascular coronary arteries. Decreased release of NO has been also reported to contribute to the increased basal tone at the coronary arterial spastic site in patients with vasospastic angina (VSA)? In support of these recent findings? we recently reported that the coronary sinus-arterial difference of the NOx concentration in patients with VSA was clearly negative and that this negative NOx difference was closely related to the elevated basal tone of the spastic coronary artery.

Asymmetric dimethylarginine (ADMA) has been recog-

(Received August 30, 2002; revised manuscript received January 6, 2003; accepted January 9, 2003)

The First Department of Internal Medicine, Niigata University School of Medicine, Niigata, *Department of Pharmacology, Kanazawa Medical University, Ishikawa and **Division of General Medicine, Niigata City General Hospital, Niigata, Japan

Mailing address: Tomoyuki Hori, MD, First Department of Internal Medicine, Niigata University School of Medicine, 1-754 Asahimachi, Niigata 951-8510, Japan nized as an endogenous, competitive inhibitor of NO synthase,, and the increased concentration of ADMA observed in hypercholesterolemic animals ${ }^{9}$ and humans ${ }^{10}$ might account for the endothelial dysfunction observed in this condition. Recently, Miyazaki et al reported that plasma concentration of ADMA was also higher in patients with coronary risk factors such as diabetes mellitus and hypertension ${ }^{11}$ which suggests that ADMA may be a risk factor for endothelial dysfunction. An intravascular ultrasound study has demonstrated that occult atherosclerosis could be present at the site of focal spasm even in the absence of angiographically significant coronary artery disease ${ }^{12}$ Although the precise mechanisms responsible for the decreased NO concentrations across the coronary circulation in patients with VSA remains unknown, increased ADMA may contribute to this abnormality. Our purpose in the present study was to elucidate the role of ADMA and its relationship to NO end-products during coronary circulation in patients with VSA.

\section{Methods}

\section{Study Patients}

Thirty-two patients were divided into 2 groups, control and VSA, on the basis of their clinical findings, including coronary angiograms.

Control Group This group comprised 13 men and 3 women whose mean age was $58 \pm 12$ years old (range, 2871) and who had atypical chest pain but coronary vasospasm could not be provoked by intracoronary infusion of 
ergonovine maleate. They had angiographically normal or nearly normal coronary arteries.

Vasospastic Angina Group (VSA Group) This group consists of comprised 15 men and 1 women whose mean age was $58 \pm 12$ years old (range, 27-76). All these patients with VSA showed angiographic coronary artery spasm associated with ischemic ST-segment changes with chest pain after intracoronary injection of ergonovine maleate, but none had significant organic stenosis $(>50 \%$ reduction in luminal diameter).

None of the study subjects had a history of myocardial infarction, valvular heart disease, congenital heart disease, peripheral arterial disease, renal dysfunction, or other serious diseases. The study protocol was approved by the Niigata University Hospital Ethics Committee. Written informed consent was obtained from each patient before cardiac catheterization. The major coronary risk factors (ie, hypertension, hypercholesterolemia (serum total cholesterol $>220 \mathrm{mg} / \mathrm{dl}$ ), diabetes mellitus and smoking) of the 2 groups were assessed.

\section{Study Protocol}

Anti-anginal drugs were discontinued at least $48 \mathrm{~h}$ before cardiac catheterization and although the use of sublingual nitroglycerin was to be permitted if needed, none of the patients used it in the $6 \mathrm{~h}$ before catheterization. All patients received underwent routine pressure and volume studies. Before coronary angiography, a sidewinder catheter was introduced into the coronary sinus and blood samples were obtained simultaneously from both the coronary sinus and the ostium of the left coronary artery. Thereafter, coronary arteriography was performed using the Judkin's technique as described previously 13 Coronary arteriograms were recorded using a Philips cineangiography system (Integris H3000). The distances from the X-ray focus to the patient, and that from the patient to the image intensifier, were kept constant during the study. After the baseline coronary arteriogram had been recorded, ergonovine was infused at $10 \mu \mathrm{g} / \mathrm{min}$ until vasospasm was provoked or until the maximal dose of $50 \mu \mathrm{g}$ had been given. In this study, coronary spasm was defined as total or subtotal occlusion of the epicardial coronary arteries associated with signs of myocardial ischemia, such as chest pain, and ischemic ST-segment changes. When chest pain or significant ST-segment deviations occurred, coronary angiography was performed immediately. If coronary artery spasm was confirmed, isosorbide dinitrate (ISDN) was administered into the left coronary artery until the coronary spasm was relieved. If not, all patients in whom coronary artery spasm was not confirmed routinely received an intracoronary injection of ISDN ( $2 \mathrm{mg})$. The heart rate, arterial pressure and a 12-lead electrocardiogram were monitored continuously.

Quantitative Coronary Angiography Quantitative assessment of the coronary arterial luminal diameter of the coronary artery was performed using a computer-assisted quantitative cardiac analyzer (CAM-1000, Nishimoto Sangyo Inc, Osaka, Japan). The luminal diameter was analyzed in the right anterior oblique position at end-diastole. For the VSA patients, we measured the luminal diameter of the left coronary artery in which the focal spasm was provoked (spasm site). In addition, the luminal diameters was measured at the proximal and distal segments of the left anterior descending coronary artery (LAD) and left circumflex artery (LCx) in both groups. The luminal diameter of the LAD was measured at the arterial origin
Table 1 Clinical Characteristics of the Study Patients

\begin{tabular}{lcc}
\hline \hline & $\begin{array}{c}\text { Control group } \\
(n=16)\end{array}$ & $\begin{array}{c}\text { VSA group } \\
(n=16)\end{array}$ \\
\hline Age (years) & $58 \pm 12$ & $58 \pm 12$ \\
M/F & $13 / 3$ & $15 / 1$ \\
Total serum cholesterol $(\mathrm{mg} / \mathrm{dl})$ & $208 \pm 37$ & $190 \pm 27$ \\
LDL cholesterol $(\mathrm{mg} / \mathrm{dl})$ & $130 \pm 41$ & $110 \pm 24$ \\
HDL cholesterol $(\mathrm{mg} / \mathrm{dl})$ & $54 \pm 18$ & $49 \pm 14$ \\
Serum triglycerides $(\mathrm{mg} / \mathrm{dl})$ & $105 \pm 32$ & $134 \pm 54$ \\
Current smoker & $12(75 \%)$ & $13(81 \%)$ \\
Hypertension & $4(25 \%)$ & $3(19 \%)$ \\
Diabetes mellitus & $7(44 \%)$ & $9(56 \%)$ \\
\hline
\end{tabular}

Values are expressed as mean $\pm S D$. HDL, high-density lipoprotein; $L D L$, lowdensity lipoprotein; VSA, vasospastic angina. $* p=N S$ for all comparisons.

(proximal) and at the point of half of the distance from way between the first major septal branch and the apex of the heart (distal). The diameter of the LCx was also measured similarly at the origins (proximal) of the artery and of the postero-lateral branch (distal). The size of the Judkin's catheter was used for calibrating the arterial diameter in millimeters.

The inter and intra-observer reproducibility of the measurements using this quantitative system were acceptable $(\mathrm{r}=0.96, \mathrm{SEE}=0.16 \mathrm{~mm}, \mathrm{p}<0.001 ;$ and $\mathrm{r}=0.98$, SEE $=$ $0.11 \mathrm{~mm}, \mathrm{p}<0.001$, respectively). The basal coronary artery tone ( $\%$ dilatation after ISDN) was calculated as:

Basal coronary artery tone $(\%)=($ Diameter after ISDNBaseline coronary artery diameter $) \times 100 /$ Baseline coronary artery diameter

Measurement of Nitrite ( $\left.\mathrm{NO}_{2}-\right)$ and Nitrate ( $\left.\mathrm{NO}_{3-}\right)$ Concentrations in Blood The blood samples obtained from the coronary sinus and the ostium of the left coronary artery were immediately heparinized $(20 \mathrm{U} / \mathrm{ml}$, final concentration) and centrifuged $\left(3,000 \mathrm{rpm}\right.$ at $4^{\circ} \mathrm{C}$ for $\left.5 \mathrm{~min}\right)$. The plasma was mixed with methanol $(1: 1 \mathrm{v} / \mathrm{v})$, and centrifuged at $10,000 \mathrm{~g}$ at $4^{\circ} \mathrm{C}$ for $10 \mathrm{~min}$ to remove the protein. The supernatant was stored at $-80^{\circ} \mathrm{C}$ until analyzed The $\mathrm{NO}_{2}^{-}$and $\mathrm{NO}_{3}^{-}$in the sample $(10 \mu \mathrm{l})$ were separated and quantified using a high-performance liquid chromatography (HPLC)-Griess system (ENO-10, EICOM, Kyoto, Japan), and the detection limit and the sensitivity of the system were both $100 \mathrm{nmol} / \mathrm{L}$ with a loading volume of $10 \mu 11^{14}$ The low concentration of heparin used had no appreciable effect on the quantification of $\mathrm{NO}_{2}{ }^{-}$and $\mathrm{NO}_{3}{ }^{-14}$ Each determination was performed in triplicate and NOx contamination arising from laboratory ware was actively excluded ${ }^{15}$ The mean \pm SEM and coefficient of variance (in parenthesis) for the intra-assay and inter-assay of pooled plasma for $\mathrm{NO}_{2}^{-}$were $0.14 \pm 0.01 \mu \mathrm{mol} / \mathrm{L}(7.7 \%)$ and $0.12 \pm 0.01 \mu \mathrm{mol} / \mathrm{L}(9.6 \%)$, respectively, and those for $\mathrm{NO}_{3}{ }^{-}$ were $29.62 \pm 0.04 \mu \mathrm{mol} / \mathrm{L}(0.33 \%)$ and $29.33 \pm 0.06 \mu \mathrm{mol} / \mathrm{L}$ $(0.47 \%)$.

Measurement of ADMA Concentrations The concentration of plasma ADMA was measured at SRL (Hachioji, Tokyo, Japan) by HPLC (Hitachi L-7480 system equipped with a fluorescence detector for excitation at $348 \mathrm{~nm}$ and emission at $450 \mathrm{~nm}$ with an ODS column) using orthophthaldialdehyde (OPA) for fluorescence determination. ${ }^{6}$ The mean \pm SD and coefficient of variance for the intraassay and inter-assay for ADMA (pooled human plasma) were $0.454 \pm 0.013 \mu \mathrm{mol} / \mathrm{L}(2.9 \%)$ and $0.456 \pm 0.011 \mu \mathrm{mol} / \mathrm{L}$ $(2.4 \%)$, respectively. 
Table 2 Angiographic Characteristics of the Control Patients

\begin{tabular}{|c|c|c|c|c|c|c|c|c|c|c|c|c|c|}
\hline \multirow{3}{*}{ Case no. } & \multirow{3}{*}{$\begin{array}{l}\text { Age (years) } \\
\text { gender }\end{array}$} & \multicolumn{6}{|c|}{$L A D$} & \multicolumn{6}{|c|}{$L C x$} \\
\hline & & \multicolumn{2}{|c|}{$\begin{array}{c}\text { Baseline } \\
\text { diameter }(\mathrm{mm})\end{array}$} & \multicolumn{2}{|c|}{$\begin{array}{c}\text { Diameter after } \\
I S D N(\mathrm{~mm})\end{array}$} & \multicolumn{2}{|c|}{$\begin{array}{l}\text { \% dilatation } \\
\text { after ISDN }\end{array}$} & \multicolumn{2}{|c|}{$\begin{array}{c}\text { Baseline } \\
\text { diameter }(\mathrm{mm})\end{array}$} & \multicolumn{2}{|c|}{$\begin{array}{l}\text { Diameter after } \\
I S D N(\mathrm{~mm}) \\
\end{array}$} & \multicolumn{2}{|c|}{$\begin{array}{l}\text { \% dilatation } \\
\text { after ISDN }\end{array}$} \\
\hline & & Prox & Distal & Prox & Distal & Prox & Distal & Prox & Distal & Prox & Distal & Prox & Distal \\
\hline 1 & $48 / M$ & 3.24 & 1.96 & 3.83 & 2.24 & 18 & 14 & 3.21 & 2.47 & 3.61 & 3.01 & 12 & 22 \\
\hline 2 & $71 / F$ & 2.44 & 2.08 & 2.68 & 2.17 & 10 & 4 & 2.09 & 1.59 & 2.23 & 2.17 & 7 & 36 \\
\hline 3 & $61 / M$ & 4.33 & 2.64 & 5.56 & 3.30 & 28 & 25 & 4.20 & 2.48 & 4.82 & 3.16 & 15 & 27 \\
\hline 4 & $65 / F$ & 3.58 & 1.79 & 4.12 & 2.15 & 15 & 20 & 3.42 & 2.15 & 3.85 & 2.95 & 13 & 37 \\
\hline 5 & $67 / M$ & 2.81 & 1.65 & 2.94 & 2.09 & 5 & 27 & 3.12 & 2.41 & 3.19 & 2.62 & 2 & 9 \\
\hline 6 & $51 / M$ & 3.16 & 1.66 & 3.25 & 1.93 & 3 & 16 & 3.02 & 2.01 & 3.27 & 2.37 & 8 & 18 \\
\hline 7 & $65 / M$ & 2.91 & 1.71 & 3.06 & 2.01 & 5 & 18 & 2.33 & 1.70 & 2.61 & 1.72 & 12 & 1 \\
\hline 8 & $71 / M$ & 4.44 & 2.24 & 4.70 & 2.52 & 6 & 13 & 3.73 & 2.17 & 4.44 & 3.92 & 19 & 18 \\
\hline 9 & $66 / M$ & 3.46 & 1.68 & 3.69 & 1.75 & 7 & 4 & 4.03 & 2.96 & 4.42 & 3.50 & 10 & 18 \\
\hline 10 & $60 / F$ & 4.01 & 2.05 & 4.47 & 2.34 & 11 & 14 & 3.62 & 2.22 & 3.92 & 2.99 & 8 & 35 \\
\hline 11 & $49 / M$ & 2.66 & 1.68 & 3.42 & 1.75 & 29 & 4 & 3.16 & 2.17 & 3.91 & 2.92 & 24 & 35 \\
\hline 12 & $42 / M$ & 2.83 & 1.91 & 3.45 & 2.32 & 22 & 21 & 2.72 & 2.24 & 2.87 & 2.32 & 6 & 4 \\
\hline 13 & $28 / F$ & 4.51 & 2.46 & 4.83 & 2.74 & 7 & 11 & 3.07 & 2.27 & 3.42 & 2.49 & 11 & 10 \\
\hline 14 & $54 / F$ & 2.00 & 1.24 & 2.40 & 1.55 & 20 & 25 & 1.96 & 1.58 & 2.40 & 2.22 & 22 & 41 \\
\hline 15 & $64 / M$ & 3.47 & 1.67 & 3.64 & 2.17 & 5 & 30 & 2.49 & 1.98 & 2.71 & 2.50 & 9 & 26 \\
\hline 16 & $61 / M$ & 5.90 & 2.12 & 6.22 & 2.73 & 5 & 29 & 3.92 & 4.28 & 4.52 & 4.50 & 15 & 5 \\
\hline
\end{tabular}

ISDN, isosorbide dinitrate; LAD, left anterior descending coronary artery; LCx, left circumflex coronay artery; prox, proximal segment; VSA, vasospastic angina.

Table 3 Angiographic Characteristics of the Patients With Vasospastic Angina

\begin{tabular}{|c|c|c|c|c|c|c|c|c|c|c|c|c|c|c|}
\hline \multirow{3}{*}{ Case no. } & \multirow{3}{*}{$\begin{array}{l}\text { Age (years) } \\
\text { gender }\end{array}$} & \multirow{3}{*}{$\begin{array}{l}\text { Spastic } \\
\text { site* }\end{array}$} & \multirow{3}{*}{$\begin{array}{l}\text { Basal } \\
\text { tone } \\
(\%)\end{array}$} & \multirow{3}{*}{$\begin{array}{c}\text { Baseline } \\
\text { diameter } \\
(\mathrm{mm})\end{array}$} & \multirow{3}{*}{$\begin{array}{l}\text { Diameter } \\
\text { after ISDN } \\
\quad(\mathrm{mm})\end{array}$} & \multirow{3}{*}{$\begin{array}{c}\text { Ergonovine } \\
\text { dose } \\
(\mu \mathrm{g})\end{array}$} & \multicolumn{4}{|c|}{$\angle A D$} & \multicolumn{4}{|c|}{$L C x$} \\
\hline & & & & & & & \multicolumn{2}{|c|}{$\begin{array}{l}\text { Baseline } \\
(\mathrm{mm})\end{array}$} & \multicolumn{2}{|c|}{$\begin{array}{l}\text { After ISDN } \\
(\mathrm{mm})\end{array}$} & \multicolumn{2}{|c|}{$\begin{array}{c}\text { Baseline } \\
(\mathrm{mm})\end{array}$} & \multicolumn{2}{|c|}{$\begin{array}{l}\text { After ISDN } \\
\quad(\mathrm{mm})\end{array}$} \\
\hline & & & & & & & Prox & Distal & Prox & Distal & Prox & Distal & Prox & Distal \\
\hline 1 & $56 / M$ & \#7 & 65 & 2.42 & 4.00 & 38 & 2.77 & 1.53 & 3.71 & 2.00 & 3.45 & 3.04 & 4.17 & 3.79 \\
\hline 2 & $66 / M$ & $\# 7$ & 60 & 1.36 & 2.17 & 40 & 3.16 & 1.82 & 4.11 & 2.42 & 2.65 & 2.33 & 3.19 & 2.95 \\
\hline 3 & $59 / M$ & $\# 7$ & 65 & 1.19 & 1.96 & 36 & 2.58 & 1.85 & 3.58 & 2.53 & 2.11 & 1.26 & 2.47 & 1.75 \\
\hline 4 & $51 / M$ & \#6 & 54 & 1.60 & 2.47 & 36 & 3.31 & 1.48 & 4.42 & 2.24 & 1.79 & 1.83 & 3.00 & 2.91 \\
\hline 5 & $69 / F$ & $\# 6$ & 27 & 1.17 & 1.49 & 40 & 2.16 & 1.32 & 2.48 & 1.79 & 1.93 & 1.93 & 2.44 & 2.34 \\
\hline 6 & $64 / M$ & $\# 13$ & 55 & 1.95 & 3.02 & 50 & 2.71 & 2.17 & 3.25 & 2.70 & 1.85 & 1.95 & 3.26 & 3.04 \\
\hline 7 & $49 / M$ & $\# 6$ & 13 & 1.50 & 1.70 & 50 & 1.75 & 1.96 & 2.00 & 2.42 & 1.86 & 1.96 & 2.20 & 2.21 \\
\hline 8 & $71 / M$ & $\# 11$ & 89 & 1.39 & 2.63 & 22 & 3.06 & 1.57 & 3.65 & 2.24 & 2.00 & 2.02 & 3.25 & 3.10 \\
\hline 9 & $67 / M$ & $\# 9$ & 28 & 1.14 & 1.46 & 50 & 2.77 & 1.63 & 2.97 & 1.90 & 2.38 & 1.70 & 2.69 & 2.15 \\
\hline 10 & $53 / M$ & $\# 13$ & 57 & 2.03 & 3.19 & 50 & 3.59 & 2.30 & 4.71 & 3.09 & 2.55 & 1.63 & 4.23 & 2.84 \\
\hline 11 & $27 / M$ & $\# 6$ & 39 & 2.12 & 2.95 & 42 & 3.28 & 1.57 & 3.49 & 1.95 & 2.96 & 2.39 & 3.47 & 2.68 \\
\hline 12 & $42 / M$ & $\# 6$ & 36 & 2.44 & 3.31 & 50 & 2.73 & 2.35 & 3.58 & 3.31 & 3.00 & 2.67 & 3.96 & 3.13 \\
\hline 13 & $56 / M$ & $\# 6$ & 15 & 1.80 & 2.07 & 50 & 2.27 & 1.66 & 2.71 & 2.00 & 2.14 & 1.57 & 2.45 & 1.83 \\
\hline 14 & $76 / M$ & $\# 11$ & 63 & 1.80 & 2.95 & 50 & 1.94 & 1.86 & 2.92 & 2.24 & 1.94 & 1.91 & 2.68 & 2.47 \\
\hline 15 & $63 / M$ & \#6 & 64 & 1.18 & 1.94 & 36 & 1.59 & 1.18 & 2.00 & 1.79 & 1.31 & 1.18 & 1.99 & 1.67 \\
\hline 16 & $58 / M$ & $\# 13$ & 46 & 1.82 & 2.67 & 46 & 3.05 & 2.09 & 3.49 & 2.57 & 2.62 & 2.12 & 3.30 & 2.74 \\
\hline
\end{tabular}

*Location of spasm site as defined by the American Heart Association. ISDN, isosorbide dinitrate; LAD, left anterior descending coronary artery; LCx, left circumflex coronary artery; prox, proximal segment; VSA, vasospastic angina.

\section{Statistical Analysis}

The NOx (V-A) difference was calculated from the NOx concentrations in the arterial blood collected from the ostium of the left coronary artery $\left(\mathrm{NOx}^{\mathrm{A}}\right)$ and that of the venous blood collected at the coronary sinus $\left(\mathrm{NOx}^{\mathrm{V}}\right)$ :

\section{$\mathrm{NOx}(\mathrm{V}-\mathrm{A})$ difference $=\mathrm{NOx}^{\mathrm{V}}-\mathrm{NO}^{\mathrm{A}}$}

In the same way, the ADMA difference was calculated:

$$
\mathrm{ADMA}(\mathrm{V}-\mathrm{A}) \text { difference }=\mathrm{ADMA}^{\mathrm{V}}-\mathrm{ADMA}^{\mathrm{A}} \text {. }
$$

All data are expressed as the means $+\mathrm{SD}$. The unpaired t-test was used to compare the results of the 2 groups. The basal left coronary artery tone values of the left coronary artery in the patients with VSA were compared using ANOVA followed by a Fisher's protected least significant difference test. Correlations between the basal coronary artery tone and NOx $(\mathrm{V}-\mathrm{A})$ difference, the ergonovine dose and basal coronary artery tone, the NOx $(\mathrm{V}-\mathrm{A})$ differ- ence and the ergonovine dose, the NOx $(\mathrm{V}-\mathrm{A})$ difference and ADMA (V-A) difference, and age and the ADMA concentration of ADMA were tested by linear regression analysis. Differences and correlations at $\mathrm{p}<0.05$ were considered statistically significant.

\section{Results}

Patients Characteristics (Table 1)

There were no significant differences between the coronary risk factors of the 2 groups.

\section{Coronary Artery Diameters at Baseline and After ISDN}

The baseline coronary artery diameters at baseline and the diameters after injection of ISDN in both groups are shown in Tables 2 and 3 . The mean baseline left coronary artery diameters at the proximal sites of the left coronary artery in the VSA patients were significantly smaller than 
those of the corresponding sites in the control patients (LAD proximal: $2.67 \pm 0.59$ vs $3.48 \pm 0.97 \mathrm{~mm}$; LCx proximal: $2.28 \pm 0.55$ vs $3.13 \pm 0.68 \mathrm{~mm}, \mathrm{p}<0.01)$. After ISDN administration, however, there were no statistically significant differences between the 2 groups (LAD proximal: $3.32 \pm 0.78$ vs $3.89 \pm 1.04 \mathrm{~mm}$; LCx proximal: $3.05 \pm 0.68$ vs $3.51 \pm 0.81 \mathrm{~mm})$.

\section{Basal Coronary Artery Tone}

The basal left coronary artery tone values at the proximal and distal sites of left coronary artery in the VSA patients were significantly greater than those at the corresponding sites in control patients (Table4). In addition, in the VSA group, the basal left coronary artery tone was significantly greater at the spastic site than that at the other sites (proximal and distal sites of the LAD and LCx) (Table 4).

Table 4 Basal Coronary Artery Tone in Control and VSA Groups

\begin{tabular}{lcc}
\hline \hline & \multicolumn{2}{c}{$\%$ Dilatation after isosorbide dinitrate (ISDN) } \\
\cline { 2 - 3 } & Control group & VSA group \\
\hline Spastic site & & $49 \pm 21^{*}$ \\
LAD & $12 \pm 9$ & \\
Proximal & $17 \pm 9$ & $24 \pm 12^{\dagger}$ \\
Distal & & $32 \pm 11^{\dagger}$ \\
LCx & $12 \pm 6$ & $35 \pm 22^{\dagger}$ \\
Proximal & $21 \pm 13$ & $34 \pm 18^{\ddagger}$ \\
Distal & & \\
\hline
\end{tabular}

Values are expressed as mean $\pm S D .{ }^{*} p<0.05$ compared with other sites in the left coronary artery in VSA patients; ${ }^{\dagger} p<0.01$ compared with the control patients; $; p<0.05$ compared with the control patients.

$L A D$, left anterior descending coronary artery; $L C x$, left circumflex coronary artery; VSA, vasospastic angina.

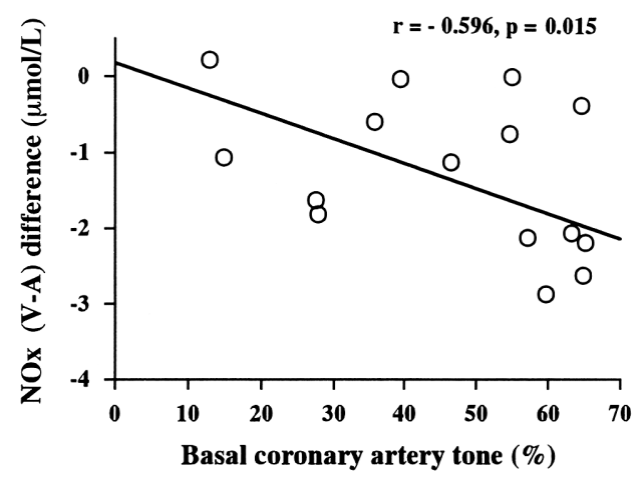

Fig 1. Relationship between basal coronary artery tone and the NOx (V-A) difference in the VSA group.

Table 5 Baseline Concentration of Plasma NOx and NOx (V-A) Difference in the Study Group

\begin{tabular}{lcc}
\hline \hline & $\begin{array}{c}\text { Control group } \\
(n=16)\end{array}$ & $\begin{array}{c}\text { VSA group } \\
(n=16)\end{array}$ \\
\hline$N_{N} x^{A}(\mu \mathrm{mol} / \mathrm{L})$ & $27.4 \pm 6.8$ & $29.7 \pm 10.3$ \\
$N O x^{V}(\mu \mathrm{mol} / \mathrm{L})$ & $27.3 \pm 6.7$ & $28.3 \pm 10.0$ \\
$N O x(V-A)$ difference $(\mu \mathrm{mol} / \mathrm{L})$ & $-0.1 \pm 0.7$ & $-1.4 \pm 1.2^{*}$ \\
\hline
\end{tabular}

Values are expressed as mean $\pm S D$. NOx ${ }^{A}$, NOx concentration in the ostium of the left coronary artery; $N O x^{V}$, NOx concentration in the coronary sinus; $N O x(V-A)$ difference, $N O x^{V}-N O x^{A}$.

$V S A$, vasospastic angina. ${ }^{*} p<0.01$ compared with the contorol patients.
Relationships Between Basal Coronary Artery Tone, NOx $(V-A)$ Difference and Ergonovine Dose

We observed a significant negative correlation between the basal coronary artery tone at the spastic site and the NOx $(\mathrm{V}-\mathrm{A})$ difference $(\mathrm{r}=-0.596, \mathrm{p}<0.05)$ in the VSA group (Fig 1), but not in the control. In addition, there was also a significant negative correlation $(r=-0.667, p<0.01)$ between the basal coronary artery tone at the spastic site and the dose of ergonovine required to provoke spasm in the VSA group (Fig 2).

\section{Basal NOx and NOx (V-A) Difference}

The baseline concentrations of plasma $\mathrm{NO}_{2}{ }^{-}$and $\mathrm{NO}_{3}{ }^{-}$in the blood from the ostium of the $\mathrm{NOx}^{\mathrm{A}}$ and those from the $\mathrm{NOx}^{\mathrm{V}}$ are shown in Table 5. The plasma $\mathrm{NOx}^{\mathrm{A}}$ and $\mathrm{NOx}^{\mathrm{V}}$ concentrations of the 2 groups were not significantly different. The NOx $(\mathrm{V}-\mathrm{A})$ difference of the VSA group was apparently negative and differed significantly from that of the control group. Thus, the VSA patients showed a significant NOx imbalance in comparison with the control group.

\section{Basal ADMA and ADMA (V-A) Differences}

The basal plasma ADMA concentrations in the ostium of the left coronary artery $\left(\mathrm{ADMA}^{\mathrm{A}}\right)$ and the ADMA $(\mathrm{V}-\mathrm{A})$ differences of the 2 groups were not significantly different (Table 6). However, the plasma ADMA concentration of the VSA group in the coronary sinus (ADMAV) was higher than that of the control group.

\section{Plasma ADMA Concentration and Risk Factors}

The concentration of ADMA showed a positive correlation with age in all 32 patients (Fig 3), though no significant relationship was recognized between age and NOx $(\mathrm{V}-\mathrm{A})$ difference. However, there was no correlation between the

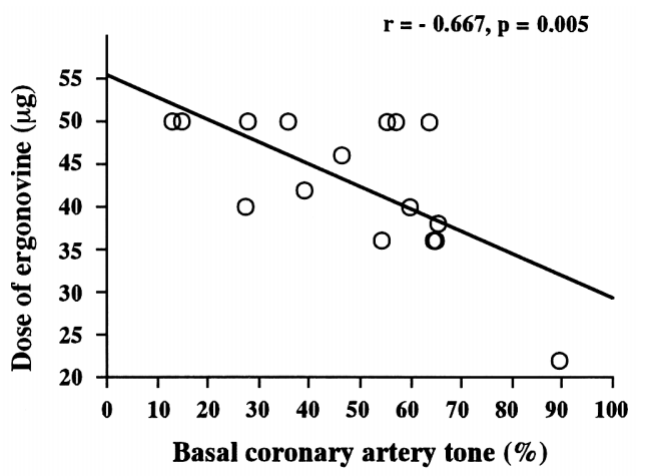

Fig 2. Relationship between basal coronary tone and the ergonovine dose required to provoke coronary artery spasm in the VSA group.

Table 6 Baseline Concentration of Plasma ADMA and ADMA (V-A) Difference in the Study Group

\begin{tabular}{lcc}
\hline \hline & $\begin{array}{c}\text { Control group } \\
(n=16)\end{array}$ & $\begin{array}{c}\text { VSA group } \\
(n=16)\end{array}$ \\
\hline$A D M A^{A}(\mu \mathrm{mol} / \mathrm{L})$ & $0.37 \pm 0.06$ & $0.41 \pm 0.06$ \\
$A D M A^{V}(\mu \mathrm{mol} / \mathrm{L})$ & $0.37 \pm 0.06$ & $0.42 \pm 0.06^{*}$ \\
$A D M A(V-A)$ difference $(\mu \mathrm{mol} / \mathrm{L})$ & $0.00 \pm 0.02$ & $0.01 \pm 0.03$ \\
\hline
\end{tabular}

Values are expressed as mean $\pm S D$. $A D M A^{A}, A D M A$ concentration in the ostium of the left coronary artery; $A D M A^{V}$, ADMA concentration in the coronary sinus; $A D M A(V-A)$ difference, $A D M A^{V}-A D M A^{A}$.

VSA, vasospastic angina. ${ }^{*} p<0.05$ compared with the contorol patients. 


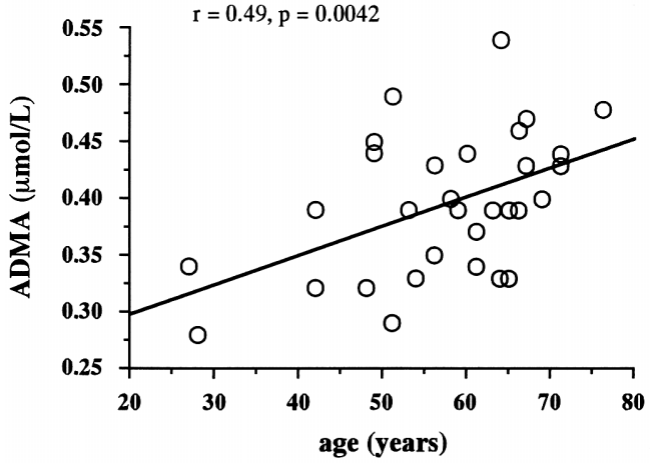

Fig 3. Relationship between the plasma concentrations of ADMA and age in all 32 study patients.

plasma ADMA concentration and cholesterol concentration (total, low-density lipoprotein (LDL), high-density lipoprotein (HDL), or triglycerides; data not shown).

\section{Relationships Between NOx $(V-A)$ Difference and ADMA $(V-A)$ Differences}

We observed a significant negative correlation between the ADMA $(\mathrm{V}-\mathrm{A})$ difference and $\mathrm{NOx}(\mathrm{V}-\mathrm{A})$ differences in the VSA group, but not in the control group (Fig 4).

\section{Discussion}

The major findings of this study are (1) the plasma concentration of ADMA in the coronary sinus was significantly higher in the VSA group than in the control group, (2) the NOx $(\mathrm{V}-\mathrm{A})$ difference (coronary sinus-arterial difference of NOx concentration) was apparently negative for the VSA group as compared with the control group, and (3) there was a significant negative correlation between the ADMA ( $\mathrm{V}-\mathrm{A})$ difference and NOx $(\mathrm{V}-\mathrm{A})$ differences across the coronary circulation in patients with VSA, but not in the control. These findings suggest that the higher concentration of ADMA in the coronary circulation is associated with the reduced NO production in patients with VSA.

In our study, the mean plasma concentration of ADMA was $0.40 \mu \mathrm{mol} / \mathrm{L}$, which is lower than that observed in another European study ${ }^{10}$ but was similar to a the value of approximately $0.51 \pm 0.01 \mu \mathrm{mol} / \mathrm{L}$ in Japanese patients reported by Miyazaki et al $!^{11} \mathrm{We}$ found that the concentration of ADMA was significantly related with aging, in good accordance with the report of Miyazaki et al!1 Therefore, our results regarding ADMA concentration are acceptable, although ethnic differences may contribute to the reported variations.

It has been demonstrated that the production of ADMA by human endothelial cells is regulated by S-adenosylhomocysteine-dependent methyltransferase, which is upregulated by native and oxidized LDL cholesterol $1{ }^{17}$ Recently, Kugiyama et al showed that the plasma concentrations of oxidized LDL were increased in patients with coronary spastic angina as compared with control patients and that these higher concentrations were a risk factor independent of other traditional risk factors for coronary spastic angina ${ }^{18}$ Furthermore, Ogawa et al reported that the mean coronary sinus-arterial difference of the plasma concentration of antioxidized LDL antibody was significantly higher in patients with coronary spastic angina than in either those
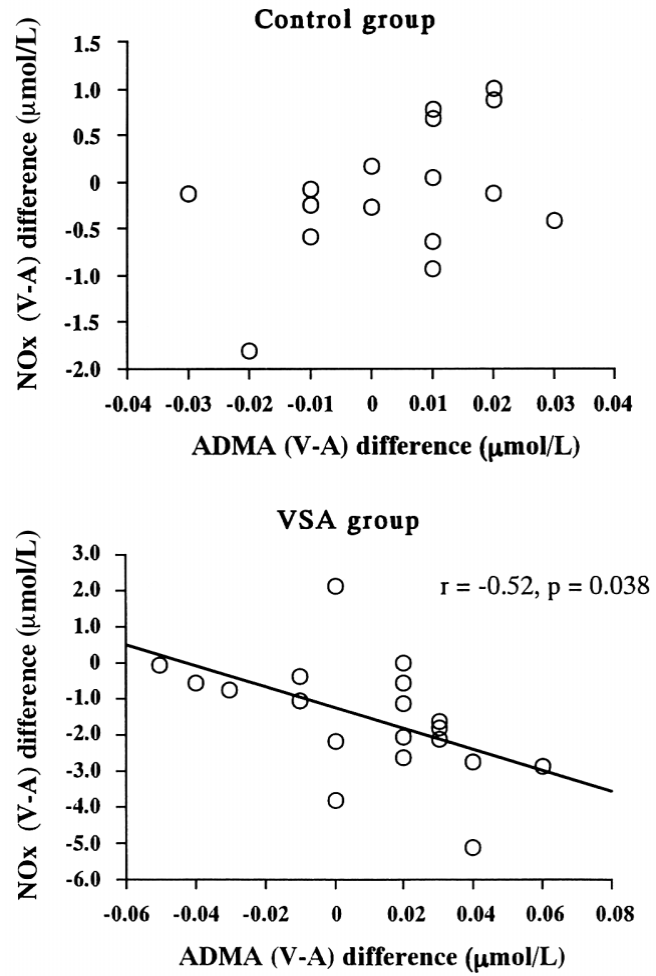

Fig 4. Relationship between the ADMA (V-A) difference and NOx $(\mathrm{V}-\mathrm{A})$ differences in the VSA group.

with stable effort angina or the control subjects $!^{19}$ In addition, several studies have indicated that the formation of oxidized LDL enhances agonist-induced coronary vascular contractions and reduces endothelium-dependent vasorelaxation? ${ }^{20,21}$ Therefore, oxidized LDL may be involved in the pathogenesis of coronary spasm via production of ADMA. Although we did not measure the concentration of oxidized LDL in the present study, those findings support our observation that the ADMA concentrations are increased in the coronary circulation of patients with VSA.

Interestingly, Böger et al demonstrated that ADMA increases superoxide radical production by cultured human endothelial cells in culture and promotes endothelial adhesion of human monocytoid cells?2 It has been shown that oxidative stress or oxygen-derived free radicals may, at least in part, play a role in the abnormal coronary vasomotor reactivity and in anginal attacks in patients with VSA ${ }^{23-25}$ Taking these considerations together, the findings indicate that in patients with VSA, oxidative stress is increased and this may be related to increased ADMA concentrations in the coronary circulation. The increased ADMA concentrations may, in turn, may increase oxygen radical production, leading to a feed-forward loop between ADMA and superoxide radicals. Therefore, not only inhibition of NO synthase by ADMA, but also reduction of the biological activity of endothelium-derived NO, would appear to contribute to pathological conditions.

It has been suggested that the basal coronary tone is elevated at the spastic coronary arterial sites in VSA patients ${ }^{7,26,27}$ and that the coronary arteries of these patients are supersensitive to the vasodilator effects of nitrates? ${ }^{28,29}$ In the present study, we observed significantly higher basal coronary tone not only at the spastic site but also at the proximal and distal segments of the left coronary arteries in 
VSA patients. Moreover, there was a significant negative correlation between the basal coronary artery tone at the spastic site and the dose of ergonovine required to provoke spasm provocation. Our results are in agreement with those of other studies?,26,29 The NOx difference in the control patients was close to zero, in agreement with our previous observations $\mathbf{s}^{7,14}$ and those of another laboratory $3^{30}$ Although a possible mechanism has been presented ${ }^{31}$ the precise details remain unknown ${ }^{32}$ However, decreased NO release from endothelium under the previously described circumstances may cause a negative NOx difference?,14 Indeed, the NOx $(\mathrm{V}-\mathrm{A})$ difference in VSA patients showed a negative correlation with the basal coronary artery tone, in good agreement with the results of our previous study? These results may assist in explaining the increased basal coronary tone in patients with VSA and the hyperreactivity to nitrate vasodilators not only of a localized segment, but also of the entire coronary tree in VSA patients. We consider that the increased coronary tone in the entire coronary artery tree of patients with VSA may be caused mainly by decreased reduced NO production in the coronary circulation and that the prominent marked increase in the basal tone of the spastic segments is clearly reflected in the decrease in the NOx concentration. Furthermore, the present study demonstrated that there was a significant negative correlation between the ADMA (V-A) difference and NOx $(\mathrm{V}-\mathrm{A})$ differences across the coronary circulation in the VSA group, but not in the control. Although the precise mechanism responsible for this decrease in the NOx concentration during coronary circulation remains unknown, the high concentration of the ADMA in the coronary circulation may be an important cause of reduced NO production in patients with VSA. However, dysfunction of endothelium would not be the sole cause of coronary vasospasm ${ }^{33}$ and that of smooth muscle should be also taken into consideration because tetrahydrobiopterin failed to prevent coronary spasm in patients with VSA, despite improvement of coronary endothelial function ${ }^{34}$

\section{Study Limitations}

One of the limitations of this study is that NOx and ADMA do not originate solely from the endothelium. In addition, we did not measure markers of oxidant stress in the coronary circulation and were unable to determine the contribution of ADMA to oxidative stress. Therefore, the present results need further investigation.

\section{Conclusions}

Patients with VSA had a negative NOx (V-A) difference in the coronary circulation, which was closely related to increased ADMA concentrations. Oxidative stress is increased in patients with VSA and thus may contribute to the higher concentration of the ADMA, establishing a feedforward loop. During coronary circulation, this mechanism would be operative in reducing the biological activity of endothelium-derived NO in spastic coronary arteries.

\section{Acknowledgments}

This work was partly supported by Grant for Promoted Research (S2001-13) and by Grant for Specially Promoted Research from Kanazawa Medical University.

\section{References}

1. Bassenge E, Busse R. Endothelial modulation of coronary tone. Prog Cardiovasc Dis 1988; 30: 340-380.
2. Luscher TF, Richard V, Tschudi M, Yang Z, Boulanger C. Endothelial control of vascular tone in large and small coronary arteries. $J$ Am Coll Cardiol 1990; 15: 512-527.

3. Moncada S, Higgs A. The L-arginine-nitric oxide pathway. $N$ Engl J Med 1993; 329: 2002-2012.

4. Quyyumi AA, Dakak N, Andrews NP, Husain S, Arora S, Gilligan $\mathrm{DM}$, et al. Nitric oxide activity in the human coronary circulation: Impact of risk factors for coronary atherosclerosis. J Clin Invest 1995; 95: 1747-1755.

5. Quyyumi AA, Dakak N, Mulcahy D, Andrews NP, Husain S, Panza JA, et al. Nitric oxide activity in the atherosclerotic human corornary circulation. J Am Coll Cardiol 1997; 29: 308-317.

6. Kugiyama K, Yasue H, Okumura K, Ogawa H, Fujimoto K, Nakano $\mathrm{K}$, et al. Nitric oxide activity is deficient in spasm arteries of patients with coronary spastic angina. Circulation 1996; 94: 266-272.

7. Hori T, Matsubara T, Ishibashi T, Yamazoe M, Ida T, Higuchi K, et al. Decrease of nitric oxide end-products during coronary circulation reflects elevated basal coronary artery tone in patients with vasospastic angina. Jpn Heart J 2000; 41: 583-595.

8. Vallance P, Leone A, Calver A, Collier J, Moncada S. Endogenous dimethylarginine as an inhibitor of nitric oxide synthesis. $J$ Cardiovasc Pharmacol. 1992; 20(Suppl 12): S60-S62.

9. $\mathrm{Yu} \mathrm{X}, \mathrm{Li} \mathrm{Y}$, Xilong Y. Increase of an endogenous inhibitor of nitric oxide synthesis in serum of high cholesterol fed rabbits. Life Sci 1994; 54: 753-758.

10. Böger RH, Bode-Böger SM, Szuba A, Tsao PS, Chan JR, Tangphao $\mathrm{O}$, et al. Asymmetric dimethylarginine (ADMA): A novel risk factor for endothelial dysfunction: Its role in hypercholesterolemia. Circulation 1998; 98: $1842-1847$.

11. Miyazaki H, Matsuoka H, Cooke JP, Usui M, Ueda S, Okuda S, et al. Endogenous nitric oxide synthase inhibitor: A novel marker of atherosclerosis. Circulation 1999; 99: 1141-1146.

12. Koyama J, Yamagishi M, Tamai J, Kawano S, Daikoku S, Miyatake $\mathrm{K}$. Comparison of vessel wall morphologic appearance at sites of focal and diffuse vasospasm by intravascular ultrasound. Am Heart $J$ 1995; 130: 440-445.

13. Igarashi Y, Yamazoe M, Shibata A. Effect of direct intracoronary administration of methylergonovine in patients with and without variant angina. Am Heart J 1991; 121: 1094-1100.

14. Ishibashi T, Matsubara T, Ida T, Hori T, Yamazoe M, Aizawa Y, et al. Negative $\mathrm{NO}_{3}$ - difference in human coronary circulation with severe atherosclerotic stenosis. Life Sci 2000; 66: 173-184.

15. Ishibashi T, Himeno M, Imaizumi N, Maejima K, Nakano S, Uchida $\mathrm{K}$, et al. NOx contamination in laboratory ware and effect of countermeasures. Nitric Oxide: Biol Chem 2000; 4: 516-525.

16. Matsuoka H, Itoh S, Kimoto M, Kohno K, Tamai O, Wada Y, et al. Asymmetrical dimethylarginine, an endogenous nitric oxide inhibitor, in experimental hypertension. Hypertension 1997; 29: 242-247.

17. Böger RH, Sydow K, Borlak J, Thum T, Lenzen H, Schubert B, et al. LDL cholesterol upregulates synthesis of asymmetrical dimethylarginine in human endothelial cells: Involvement of S-adenosylmethiomine-dependent methyltansferases. Circ Res 2000; 87: 99-105.

18. Kugiyama K, Sugiyama S, Soejima H, Kawano H, Sakamoto T, Takazoe K, et al. Increase in plasma levels of oxidized low-density lipoproteins in patients coronary spastic angina. Atherosclerosis 2001; 154: 463-467.

19. Ogawa H, Soejima H, Takazoe K, Miyamoto S, Kajiwara I, Shimomura $\mathrm{H}$, et al. Increased autoantibodies against oxidized low-density lipoprotein in coronary circulation in patients with coronary spastic angina. Angiology 2001; 52: 167-174.

20. Kugiyama K, Kerns SA, Morisett JD, Roberts R, Henry PD. Impairment of endothelium-dependent arterial relaxation by lysolecithin in modified low-density lipoproteins. Nature 1990; 344: 160-162.

21. Galle J, Bassenge E, Busse R. Oxidized low density lipoproteins potentiate vasoconstrictions to various agonists by direct interaction with vascular smooth muscle. Circ Res 1990; 66: 1287-1293.

22. Bode-Böger SM, Tsao PS, Lin PS, Chan JR, Cook JP. An endogenous inhibitor of nitric oxide synthase regulates endothelial adhesiveness for monocytes. J Am Coll Cardiol 2000; 36: 2287-2295.

23. Miwa K, Miyagi Y, Fujita M. Susceptibility of plasma low density lipoprotein to cupric ion-induced peroxidation in patients with variant angina. J Am Coll Cardiol 1995; 26: 632-638.

24. Kugiyama K, Motoyama T, Hirashima O, Ohgushi M, Soejima H, Misumi K, et al. Vitamin C attenuates abnormal vasomotor reactivity in spasm coronary arteries in patients with coronary spastic angina. $J$ Am Coll Cardiol 1998; 32: 103-109.

25. Motoyama T, Kawano H, Kugiyama K, Hirashima O, Ohgushi M, Tsunoda R, et al. Vitamin E administration improves impairment of endothelium-dependent vasodilatation in patients with coronary spastic angina. J Am Coll Cardiol 1998; 32: 1672-1679. 
26. Kuga T, Egashira K, Iou T, Takeshita A. Correlation of basal coronary artery tone with constrictive response to ergonovine in patients with variant angina. J Am Coll Cardiol 1993; 22: 144-150.

27. Hoshino A, Kotake H, Mashiba H. Significance of coronary artery tone in patients with variant angina. J Am Coll Cardiol 1989; 14: 604-609.

28. Okumura K, Yasue H, Matsuyama K, Ogawa H, Kugiyama K, Ishizaka $\mathrm{H}$, et al. Diffuse disorder of coronary artery vasomotility in patients with coronary spastic angina: Hyperreactivity to the constrictor effects of acetylcholine and the dilator effects of nitroglycerin. $J \mathrm{Am}$ Coll Cardiol 1996; 27: 2745-2752.

29. Kugiyama K, Ohgushi M, Sugiyama S, Motoyama T, Kawano H, Hirashima O, et al. Supersensitive dilator response to nitroglycerin but not to atrial natriuretic peptide in spastic coronary arteries in coronary spastic angina. Am J Cardiol 1997; 79: 606-610.

30. Traverse JH, Wang YL, Du RS, Nelson D, Lindstrom P, Archer SL, et al. Coronary nitric oxide production in response to exercise and endothelium-dependent agonists. Circulation 2000; 101: $2526-$ 2531.

31. Recchia FA, Vogal TR, Hintze TH. NO metabolites accumulate in erythrocytes in proportion to carbon dioxide and bicarbonate concentration. Am J Physiol Heart Circ Physiol 2000; 279: H852-H856.

32. Ishibashi T, Kubota K, Himeno M, Matsubara T, Hori T, Ozaki K, et al. Respiratory alkalosis does not alter NOx concentrations in human plasma and erythrocytes. Am J Physiol Heart Circ Physiol 2001; 281: $\mathrm{H} 2757-\mathrm{H} 2761$.

33. Shimokawa H. Cellular and molecular mechanisms of coronary artery spasm: Lessons from animal models. Jpn Circ J. 2000; 64: 1-12.

34. Fukuda $Y$, Teragawa $H$, Matsuda $K$, Yamagata $T$, Matsuura $H$, Chayama K. Tetrahydrobiopterin improves coronary endothelial dysfunction, but does not prevent coronary spasm in patients with vasospastic angina. Circ J 2002; 66: 58-62. 